\title{
Lada Stevanović
}

lada.stevanovic@gmail.com

\section{Magična moć opscenih reči u ženskoj reveni*}

\begin{abstract}
Stevanović Lada, Magična moć opscenih reči u ženskoj reveni (Magic Power of the Obscene Language in Womens' Revena). „Poznańskie Studia Slawistyczne” 3. Poznań 2012. Adam Mickiewicz University Press, pp. 173-186. ISBN 978-83-232-2473-0. ISSN 2084-3011.

The theme of this paper is the magic power of the obscene words and jokes in traditional Serbian culture, on the example of women's only festival revena in Banat. This ritual represents one day holiday that was celebrated in the beginning of spring, before the Eastern Fast During revena women gathered for a celebration during which their behavior was completely different than usual, transgressing all the strict norms that prevailed in everyday reality of patriarchal society. Except for the excessive drinking and eating, women expressed their sexuality freely and they spoke about it in the most obscene way. Apart from the verbal part, the ritual of revena had also its performative side. Thus women were proving their female sex by raising the skirt (in the Kumane village), and this act functioned as some kind of pass to enter the revena. During the holiday, some women were dressed up as men in order to fulfill the necessary male roles for the sexual games, because no man (except for the musician) was allowed to be present on this holiday. The analysis in this paper, devoted above all to the magic power of the obscene language in the traditional culture, is inscribed into the Bakhtin's theory of carnival. It is applied here not only to the carnivalesque behavior, but also to the concrete verbal obscene content. These obscenities are inseparable from laughter so the magic power of laughter (as defined by Veselin Čajkanović) is also analyzed in this paper, and, apart from appearing in revena, it represented important part of the funeral ritual.
\end{abstract}

Keywords: obscene language, revena, magical laughter, life, death, Bakhtin

Ovaj rad posvećen je magijskoj moći opscenih reči i sa njima povezanim magijskim smehom u tradicionalnoj srpskoj kulturi - pre svega u ritualu ženske revene. Budući da kontekst o kome je reč pripada minulim vremenima, treba uzeti u obzir da tradicionalni ritual može čuvati različite

* Tekst je nastao kao rezultat rada na projektu „Kulturno nasleđe i identitet”, br. 177026, koje finansira Ministarstvo prosvete, nauke i tehnološkog razvoja Republike Srbije. 
slojeve okamenjenih i često napuštenih i zaboravljenih značenja ${ }^{1}$ i upravo to je razlog što se upuštam u ovu analizu - da rasvetlim najstarije slojeve značenja lascivnog govora i njegovu magičnu moć koja je zaboravljena i koja se očuvala (doduše nesvesno) možda samo u jednom funkcionalnom segmentu savremene psovke, i to kada ona služi kao uzrečica za emotivno pražnjenje ili kada se koristi u šali, ali svakako ne kada joj je isključiva funkcija da drugog uvredi.

Da bismo otkrili najstarije slojeve značenja opscenosti i njihovu magičnu moć, važno je zagaziti dublje u prošlost. Pođimo zato od tradicinalnog rituala, i to od revene. Naziv samoga obreda zapravo obuhvata šire značenje i koristi se za označavanje različitih vrsta udruživanja u jelu i piću uključujući i zajedničko izmirivanje troškova ${ }^{2}$. Ja ću se, međutim, ograničiti na jedan tip revene koja se slavila do sedme ili osme decenije dvadesetog veka u Banatu i to kao praznik u kome su učestvovale isključivo žene i u kome, kao što ćemo videti, opscenosti i lascivni govor imaju zapaženo mesto, ali i vrlo jasnu magičnu funkciju u okviru obreda. Kao što naglašava Miroslava Malešević u svom sjajnom i analitičkom radu koji je posvećen ovom prazniku pod nazivom Dan raspusnog življenja ${ }^{3}$, ovaj ženski praznik nema ništa zajedničko sa muškim revenama u kojima je, jelo i piće samo sebi svrha bilo kojom praktičnom prigodom, ženama je obilje hrane i piće samo povod ili neophodna «scenografija» za mnogo složeniju ritualnu predstavu koju su izvodile jedanput godišnje u okviru preduskršnjeg obrednog kompleksa"4. Reč je o obredu koji je padao u vreme smene godišnjih doba, početkom proleća. Iako je umeštena u hrišćanski kalendar, činjenica je da revena - praznik plodnosti - ukazuje na poreklo koje seže $\mathrm{u}$ daleku prošlost ${ }^{5}$.

${ }^{1}$ O. Freidenberg, Poètika sjužeta i žanra, Moskva 1997, str. 238.

${ }^{2}$ Sama reč je persijsko-turskog porekla (s.v. refena) i koristila se za organizovano jelo i piće na vašarima, seoskim i crkvenim slavama, različitim praznicima, kao i posle obavljenih poslova, a o zajedničkom trošku u različitim krajevima Srbije, Hrvatske i Bosne. M. Milosavljević, Revena - običajno-pravno udruživanje ljudi u jelu i piću, Novi Sad 1971, str. 335; M. Malešević, Dan raspusnog življenja u: eadem, Žensko. Etnografski aspekti društvenog položaja žene u Srbiji, Beograd 2007, str. 73.

${ }^{3}$ M. Malešević, op. cit., str. 73-88.

${ }^{4}$ Ibidem, str. 74.

${ }^{5}$ Za ljudsku svest na agrarnom nivou kada se smatra da su nastali praznici plodnosti, osobeno je izjednačavanje ljudi sa biljnim svetom, uključujući i process cikličnosti. O. Freidenberg, op. cit., str. 177. 
U selima oko Rudnika i u Kačeru je postojao sličan običaj, takođe početkom proleća, između Mladenaca i Blagovesti. Naime, u vreme vrbopuca, tj. pupljenja vrbe, udate žene igrale su kolo pod imenom „kobile”. U ovom kolu učesnice su se jednom rukom držale za drugu ženu, a u drugoj su držale preslicu ili malu granu. Sam ples bio je orgijastičke prirode, igralo se uz poskakivanje i uz oponašanje kobile, a isto kao i na reveni i u ovom kolu, muškarcima je bio izričito zabranjen pristup, a onoga koji bi zalutao, učesnice bi udarale preslicom ili granom ${ }^{6}$. Slično kolo igralo se u Banatu, u nekim selima Bačke i Srema o Belim pokladama. I ovo je kolo, poput vrbopuca, posedovalo orgijastičke elemente, sa funkcijom buđenja i osnaživanja plodnosti. Ponegde su igrale samo babe, a ponegde je kolo vodio pop (verovatno funkcionišući kao stari muški demon), ili mlađa trudna žena ${ }^{7}$ (ovaploćenje plodnosti u svom zenitu, uoči porođaja).

Prema proučavanju Miroslave Malešević, revena se održavala neposredno pred početak uskršnjeg posta, na Čisti ponedeljak. To je bio i dan kada se izvršavalo čišćenje posuđa koje se koristilo za spremanje mrsne hrane, ali i dan pripreme za večernji praznik. Revenalo se po kućama ili u kafanama, a učesnica je bilo između deset i dvadeset ${ }^{8}$. Izuzev muzičarima, muškarcima je na revenu pristup bio strogo zabranjen, a kada bi neko muško ipak zalutalo na ovu raspusnu svečanost (što se retko događalo), učesnice ga ne bi baš rastrgle golim rukama kao što su, u istoj prilici, to učinile Bahantkinje Penteju', ali bi ga svakako oštro kaznile zbog stupanja u prostor koji je isključivo ženski i u kome, bar jedan dan, žene imaju sva prava koja su im u drugim prilikama uskraćena. Žene bi zajednički nasrnule na uljeza uglavnom verbalno, lascivno ga ismevajući, a kako je čitav praznik odisao razuzdanošću, dešavalo se i da ga fizički napadnu i razgolite.

${ }^{6}$ SMR, s.v. vrbopuc. (Skraćenica SMR u ovom radu označava: Š. Kulišić, P.Ž. Petrović, N. Pantelić, Srpski mitološki rečnik, Beograd 1970.)

${ }^{7}$ SMR, s.v. oro.

${ }^{8}$ M. Malešević, op. cit., str. 75.

${ }^{9}$ Ovaj mit, prema kome su Bahantkinje rastrgle i pojele Penteja koji je posmatrao njihov, za muškarce zabranjen, ekstatični ples i to tako što se prerušio u ženu - poslužio je Euripidu kao predložak na osnovu koga je napisao dramu Bahantkinje. Iako je ovde nesumnjivo reč o mitu, u grčkoj antici su postojali praznici nalik reveni u kojima su učestvovale isključivo žene i na kojima je muškarcima bio strogo zabranjen pristup. 
Najpopularniji i najrašireniji praznik ovog tipa u antičkoj Grčkoj bile su Tesmoforije, posvećene boginji Demetri i one su se (a to je bila retkost za praznički kalendar antičkih Grka) slavile gotovo u čitavom grčkom svetu u vreme žetve ${ }^{10}$. Ovim su praznikom žene obezbeđivale plodnost čitavog polisa i premda su muškarci finansirali praznik, pristup im je bio strogo zabranjen ${ }^{11}$. Osim muškarcima učešće nije bilo dozvoljeno ni deci ni devicama. Za vreme tesmoforija žene su koristile retku priliku da ostanu van kuće ne samo čitav dan, već i noć (zapravo u Atini, Sparti i Abderi praznik je trajao tri dana, a prethodila su mu još i dva dana uvodnih svečanosti). Ovu vrstu praznika karakterisala je sloboda, razuzdanost, ženska autonomija, osvajanje javnog prostora i opsceni govor ${ }^{12}$, a mitološki predložak opscenog jezika na Tesmoforijama predstavlja Homerska himna Demetri u kojoj je opisan mit o Hadovoj otmici Persefone i Demetrinoj patnji. Prema mitu, Had, bog podzemlja oteo je Persefonu, Demetrinu ćerku. Demetra je očajna od tuge i bola prestala da jede, ali je i kao boginja prirode i plodnosti učinila da na zemlji zavlada pustoš i glad. Prema jednoj verziji mita pojavila se starica Jamba koja je Demetru nasmejala lascivnim šalama i vratila joj volju za životom, a prema drugoj verziji, zaslužna za oporavak boginje, a time i čitave prirode, bila je starica Baubo koja je podigla suknju i pokazala svoje genitalije ${ }^{13}$. Usledio je Demetrin smeh i čitava priroda je oživela.

Iako su žene bile potisnute u drugi plan u patrijarhalnim društvima, ipak im se moć u sferi života nije mogla osporiti. Osim sposobnosti da rađaju, žene su u tradicionalnim društvima uspele da očuvaju dominantnu

\footnotetext{
${ }^{10}$ Mnogi istraživači se slažu u tome da zapažena ženska uloga u ovim praznicima predstavlja neku vrstu kompenzacije za oficijelne pokušaje ograničavanja uloge koju su žene imale u pogrebnom ritualu. N. Loraux, Mothers in Mourning, Ithaca 1998, str. 21; G. Holst-Warhaft, Dangerous Voices: Women's Lament and Greek Literature, Patsdow-Cornwall 1995, str. 100.

${ }^{11}$ W. Burkert, Greek Religion, New York 1985, str. 242.

${ }^{12} \mathrm{~J}$. Winkler, The Laughter of the Oppressed: Demeter and the Gardens of Adonis, New York-London 1991, str. 194; F. Zeitlin, Travesties of Gender and Genre in Aristophanes' Thesmophoriazousae in Playing the Other, Chicago-London 1996, str. 401.

${ }^{13}$ H. Foley, The Homeric Hymn to Demeter: Translation, Commentary and Interpretative Essays, Princeton 1994, str. XII.
} 
ulogu u pogrebnim ritualima ${ }^{14}$. Stoga je ženama mesto na ovakvom prazniku i pripalo upravo kao glavnim nositeljkama života i plodnosti, a sa ovom svojom moći su na ritualnom zadatku revenanja one dolazile u kontakt kroz niz opscenih šala, pesama i igrokaza koje su izvodile. Neke od žena prerušile bi se u muškarce kako bi upotpunile skečeve sa temom seksualnosti koja je u ovom ritualnom kontekstu (a i što se tiče žena u tradicionalnom društvu opšte) podrazumevala samo jednu funkciju životvornu, iako su seksualni kontakti u prazniku, bilo glumljeni, bilo verbalizovani, bili gotovo po pravilu ,neregulisani” i oslobođeni svih uobičajnih normi, podrazumevajući vanbračne, čak i višestruke ljubavničke odnose. Ženska travestija je u ovom ritualu dakle imala isključivo funkciju da obezbedi muške aktere (jer muškarcima je učešće bilo izričito zabranjeno $^{15}$ ) kako bi se ostvario glumljeni (hetero)seksualni odnos za obezbeđivanje plodnost. Tako je npr. u okviru malog banatskog kola koje se igralo na reveni, a u kome su svi učesnici (̌̌ene, muškarci, svekrva, svekar, zaova) uzvikivali nešto lascivno, zaova zapevala: „Ja, zaova - dobre sreće, Jedan vadi - drugi meće" ${ }^{\prime 6}$. Osim lascivnog izražavanja, žene su se neprekidno pipkale, štipkale, a katkada podizale suknje otkrivajući svoje genitalije i sve je to imalo jednu te istu magijsku funkciju - da podstakne i osnaži sile života i plodnosti ${ }^{17}$.

${ }^{14}$ Kroz istoriju Balkana, od zakonodavca Solona (VII-VI v. p.n.e) pa do modernog doba, nije bilo zakona koji je ženama mogao oduzeti tako važnu nadležnost kao što je briga o mrtvima, pa su i narikače izražavle svoju tugu, ali i mišljenje o smrti, bez obzira na to što se, nakon širenja hiršćanstva i Crkva zvanično pobrinula da obezbedi opelo. Dakle, dok je sfera javnog pripadala muškarcima, žene su bile zadužene za rituale, za dom i za ono centralno u njemu, a to je život. Nadležnost i briga su na početku (sa trudnoćom, porođajem i brigom oko dece) i na kraju života (uključujući čitav pogrebni ritual) pripadali ženama. One su zbog toga bile obeležene ritualnom nečistoćom (gr. Miasma) i smatralo se da su ,uprljane", ali im je ipak priznavana moć.

${ }^{15}$ Miroslava Malešević u ovom izbacivanju muškarca vidi tragove mita o „odstranjenom muškarcu', koji prema ovoj autorki pomaže stvaranje osećaja ženskog zajedništva, kao i jake, nezavisne žene. M. Malešević, op. cit., str. 81; I. Čolović, Dan za mušku finoću. Mitoanaliza jednog praznika, Beograd 1972, str. 893.

${ }^{16}$ B. Zarić, Revena je ženski svetac pravi, Novi Sad 2001 [CD-ROM]; G. Roganović, M. Gajić, Građa entomuzikološkog terenskog istraživanja u Kikindi, Kikinda 2006 [CD-ROM]; S. Asanović, Revena u Kikindi, „Etnoumlje” god. 2, br. 3, 2008, str. 40-47; <http://www.worldmusic.autentik.net/magazin_etnoumlje_br_3.pdf> [preuzeto: 19.6.2012].

${ }^{17}$ Ovo asocira na već spomenuti mit o Demetri i Persefoni i to na verziju u kojoj je starica Baubo nasmejala Demetru podizanjem suknje i pokazivanjem svojih genitalija. 
Ovo lascivno ponašanje i opsceni humor neodvojivi od ženskog revenanja, mogu se shvatiti imitativno - imenovanje seksualnih organa i glumljenje seksualnih činova imali su smisao da osnaže plodnost i životne sile. Stav Vladimira Propa je da su religijski motivi koji su prvobitno sigurno bili povezani sa ovakvim ponašanjem vrlo brzo nestali iz svesti učesnica, a da je ostalo zadovoljstvo ritualnog smeha i uživanja na ovim praznicima $^{18}$.

Nema sumnje da ritualno ponašanje učesnica revene možemo povezati i sa Bahtinovim shvatanjem karnevala i njegovim konceptom narodne smehovne kulture. Naime, u knjizi Stvaralaštvo Fransoa Rablea, narodna kultura srednjeg veka $i$ renesanse, Bahtin razvija svoj čuveni koncept karnevala koji se zasniva na ideji o paralelnom postojanju dva životna svetonazora koji su postojali u Evropi još od antičkog doba. Njegova teza je da, osim zvančinog pogleda na svet koji je zasnovan na ozbiljnosti i hijerarhiji, postoji i svetonazor koji je uvek obojen smehom. Iščitavanjem Bahtina postaje jasno da se ovaj ,neozbiljni” pogled na svet, ova „smešna strana života" ne pojavljuje kao odgovor na oficijelne vrednosti (iako bez sumnje može na taj način funkcionisati), već ima dugu tradiciju koja se očuvala upravo u parodičnim kultovima, u karnevalskim svečanostima, opscenom jeziku i narodnoj smehovnoj književnosti ${ }^{19}$. Dakle, kada govorimo o reveni jasno je da govorimo o vrsti karnevalskog praznika u kome su svet i pravila koja vladaju u njemu izokrenuti naglavačke, u kome dominiraju lascivnost, izražena seksualnost i psovke. Svakodnevica i vrednosti koje inače postoje potpuno su poništene, omalovažene i narušene, pa upravo tu leži moć kojom se sile života osnažuju i kojima se podstiče obnova. Za ovaj veseli i razuzdani praznik je bila pripremana obilna gozba, pa se uz obije hrane uživalo i u nekontrolisanom ispijanju rakije $\mathrm{i}$ vina, što je svakako pomagalo razbijanju društvenih okova koji su sprečavali žene da se češće ponašaju na taj način. Mihail Bahtin ističe da u situacijama kada se jede i pije u izobilju dolazi da brisanja granica između tela i spoljašnjeg okruženja, što dovodi do trijumfa tela nad svetom koji ga okružuje. Telo slavi pobedu i upravo je to razlog što ne postoji gozba na kojoj se jede i pije, a koja je tužna. To je trijumf života nad smrću u kome pobedničko telo

${ }^{18}$ V. Propp, Problemy komizma i smeha, Moskva 1999, str. 167.

${ }^{19}$ M. Bahtin, Stvaralaštvo Fransoa Rablea, narodna kultura srednjeg veka i renesanse, prev. I. Šop, T. Vučković, Beograd 1978, str. 10-12. 
konzumira svet obnavljajući se ${ }^{20}$. Ovaj trijumf života, kao što ću pokazati, ostvarivaće se u reveni na više nivoa i načina.

Iako praznici poput revene ne poštuju autoritete i za trenutak se čini kao da prkose postojećem poretku, najintrigantnije pitanje koje se postavlja u vezi sa ženskim praznicima plodnosti, a s obzirom na žensku autonomiju osobenu za njih jeste - kakve su posledice ovih praznika u svakodnevici, tj. da li oni ugrožavaju ili reafirmišu postojeći poredak. Walter Burkert smatra da oni zapravo samo predstavljaju ventil za splašnjavanje antagonizama između muškaraca i žena ${ }^{21}$. Sa druge strane, Laurie O'Higgins koja se bavila pre svega antičkim grčkim ženskim praznicima poput Tesmoforija, jedna je od retkih autorki koja eksplicitno naglašava da je ovaj tip praznika u kome su dominirali ženska razuzdanost i lascivni govor bio prilika za revoluciju $^{22}$. Sa ovim radikalnim stanovištem teško je složiti se u potpunosti, iako je vrlo moguće da su se žene nakon praznika osećale osnaženo i ohrabreno u svakodnevici koja bi usledila kada bi se praznik završio. Bahtinovo stanovište je da su zapravo ovi praznici upravo i regulisani time što im je trajanje ograničeno, pa se sve norme, vrednosti i pravila ponovo uspostavljaju onog trenutka kada se praznik okonča ${ }^{23}$.

Učesnice ritualnog revenanja nazivane su „babe”, a to je reč iz dečijeg rečnika nastala reduplikacijom, koja znači ,stara žena, djedova žena; u prenesenom značenju prema bavljenju s djecom, dadilja" ${ }^{24}$. Miroslava Malešević smatra da razlog za korišćenje ove reči u ritualu leži u godištu učesnica koje su bile uglavnom sredovečne ili starije, ali u svakom slučaju se radilo o ženama koje su već ostvarile svoju reproduktivnu funkciju

${ }^{20}$ Ibidem, str. 299-300.

${ }^{21}$ W. Burkert, Creation of the Sacred: tracks of Biology in Early Religions, Harvard 1998, str. 105.

${ }^{22}$ O'Higgins, Women's Cultic Joking and Mockery in Making Silence Speak: Women's Voices in Greek Literature and Society, ed. by M. Lardinios, L. McClure, PrincetonOxford 2001, str. 153-156.

${ }^{23}$ M. Bahtin, op. cit., str. 17.

${ }^{24}$ Skok, s.v. baba. (Skraćenica Skok u ovom radu označava: P. Skok, Etimologijski rječnik hrvatskoga ili srpskoga jezika, Zagreb 1971.) 
(devojke i mlade neveste nisu uzimale učešće u prazniku), te u tom smislu ova autorka smatra da: „Njihova uloga u ritualu, kao bića koja otelovljuju samu proizvodnju života, jeste da sopstvenim primerom stimulišu rast i rađanje" ${ }^{25}$. Nema sumnje da ove žene zaista predstavljaju otelotvorenje životvornosti budući da su svoju plodnost već potvrdile ${ }^{26}$, ali da li razlog što se učesnice rituala nazivaju babama leži u njihovoj sredovečnosti (a sredovečna žena ipak nije starica, tj. „baba”) ili odgovor na ovo pitanje treba tražiti u tradicionalnim verovanjima?

Prema interpretacijama i rekonstrukcijama istraživanja istorije religije smatra se da je jedno od najznačajnijih starih srpskih božanstava bila velika boginja plodnosti (koja je značajna i za druge indoveropske narode), čije nam je ime, zbog tabua, ostalo nepoznato, a za koju se u narodu koristio eufemistički naziv Baba što je posvedočeno u toponimiji (planina Baba, Babin dub, Babino jezero, Babina glava, Babina gora, Babino polje, Babina rijeka itd) i nazivima biljaka (babina duša, babin zub, babina svila itd). Prema bosanskom verovanju u velikim jamama žive divje babe, koje imaju u toj jami sudove i rade sve ono što se radi na zemlji. To je dakle jama koja predstavlja podzemni svet u kome se „krčka” plodnost i ,priprema" novi život ${ }^{27}$. Zanimljivo je da su mnoge Babe u tradiciji koja nam je očuvana zamišljane kao veoma opasni demoni (a demoni su unižena stara božanstva) koje je trebalo poštovati da bi se obezbedila njihova zaštita i da bi se sačuvala pre svega deca (Baba Jega, Baba Jaga, Baba Roga, Baba Ruga). Baba Korizma je npr. zamišljana kao stara, mršava i visoka žena koja je za vreme posta išla po kućama i kažnjavala decu koja ne poste, odnoseći ih u jamu ${ }^{28}$, dok su babice bile demoni opasni po decu u prvih 40 dana od rođenja. Zanimljivo je da se ista reč, babica, koristi za ženu koja pomaže pri porođaju i oko novorođenčeta i koja se danas, čak $\mathrm{u}$ institucionalizovanim medicinskim ustanovama, u kojima se hijerarhija strogo poštuje a lekari uživaju najveći ugled, smatra na porođaju često važnijom od doktora. Ova ambivalencija u vezi sa „babama” i „babicama”

${ }^{25}$ M. Malešević, op. cit., str. 78.

${ }^{26}$ Ibidem.

27 V. Čajkanović, Studije iz srpske religije i folkora 1925-1942, Beograd 1994, str. 104

${ }^{28}$ SMR, s.v. Baba Korizma. 
sugeriše da je korišćenje reči „baba” u reveni povezano sa kultom boginje plodnosti, za koju se nekada verovalo da gospodari silama života i smrti i kao takva predstavlja potencijalno najsposobniju životnu zaštitnicu i najveću opasnost po život. Jer, ne treba zaboraviti, u paganskim verovanjima nije bilo pozitivnih i negativnih božanstava, već su sva ona mogla delovati, u zavisnosti od okolnosti i poštovanja njihovog kulta, dobronamerno i zlonamerno.

Zanimljivo je da je u nekim selima za vreme revene jedna od žena bila prerušena u popa koji bi najpre okadio sve prisutne redom i celu prostoriju, a onda bi se i ,prikrstio" i izgovorio Oče naš ${ }^{29}$ :

Voj mi oca, ubio sin oca, ako da Bog - i ja ću mog!

Oče naši, našoj snaši, celim putem kuma plaši

Kako ima čudne stvari - svoga kuma da opari.

Starom svatu belencuge - opletene od tri struke

Od svileni njeni dlaka.

A starojku - svu krznicu - natakla je na budžicu.

Mladoženja samo - hik! - štuca, da je osto i bez kurca.

A vi gosti, sačekajte, dok se gara ne odere - biće vama ponajbolje!

Danas huka, sutra buka, prekosutra svekru muka,

Kad se stane računati - svu će kitu počupati!

Stigla prija iz Iđoša - buri pizdu na Miloša

Miloš vadi, pa ga gladi - da joj turi - da procuri.

Ajte gosti, jejte supe - da vas jebem sve u dupe!

Ko ne kaže - amin - umrla mu žena!

Dakle, mi ovde, osim potpuno slobodnog, lascivnog i razuzdanog govora, možemo uočiti još jedan važan element, a to je ne samo razbijanje konvencionalnih normi ponašanja koje su važile za ženu u patrijarhalnom društvu, već i parodiranje glavnog čuvara društvenog morala u tradicionalnom društvu, a to je Crkva. I na ovom mestu se možemo pozvati na Bahtina koji je u narodnu smehovnu kulturu uključio i književna smehovna

\footnotetext{
${ }^{29}$ B. Zarić, op. cit.; G. Roganović, M. Gajić, op. cit.; S. Asanović, op. cit.
} 
dela (pismena ili usmena), čiju je tradiciju pratio od antike kroz čitav srednji vek. Ove književne tvorevine su uglavnom bile vezane za crkve i manastire. Bilo da su nastajala na latinskom ili narodnom jeziku, ta su dela spuštala svete spise na materijalno-telesni plan uvodeći elemente opscenog i lascivnog. Dakle, spomenuti Oče naš iz revene karakterišu identični parodijski elementi koje je prepoznao Bahtin i koji svakako parodiraju i izokreću hrišćanske vrednosti. Prema Bahtinu, ovo snižavanje ne treba shvatiti kao metaforu, već bukvalno, kao snižavanje onoga što je gore, na ono što je dole, u zemlju i u grob, koji zapravo predstavljaju utrobu iz koje se rađa novi život. Ta topografija ukazuje na direktnu vezu između kosmičkog i telesnog koji nigde nisu razgraničeni i to je razlog što spominjanje reproduktivnih organa nosi ogromnu magičnu moć. Jer oni označavaju ono što je dole, koje označava smrt, ali istovremeno i novi život $^{30}$. Vratimo se, u ovom kontekstu, na prvi stih koji sadrži motiv oceubistva i koji takođe ima funkciju da izazove smeh - pre svega kroz spuštanje u grob, a potom i kroz igru reči (Voj mi oca, ubio sin oca) i kako nam se iz vlastite perspektive čini, kao jedan potpuno neočekivani obrt. Ali, da li je na ovom mestu reč samo o igri reči ili je posredi nešto drugo, videćemo malo kasnije. Najpre je važno da se pozabavimo elementima na koje nas ovaj stih upućuje, a to su smrt i smeh.

U okviru pogrebnog rituala (u kome su žene, isto kao i u reveni, imale centralnu ulogu), pre svega za vreme bdenja i daća, naročito u prošlosti i na pogrebima mladih ljudi, potpuno neočekivano, nelogično i bez emotivne opravdanosti pojavljivao se smeh. U uslovima smrti i tabua koji smrt okružuje, smeh o kome govorimo, prema tvrdnjama Veselina Čajkanovića, može biti isključivo opravdan funkcijom koju dobija u ritualu. Polazeći od stanovišta da je obrede moguće analizirati uz pomoć folklornog materijala, budući da i jedni i drugi čuvaju okamenjene slojeve verovanja i značenja različita po starini, Čajkanović započinje analizu smeha citatom narodne pesme Smrt cara Uroša. Mladi Uroš odlazi sa ujakom Vukašinom u lov da bi na ovom pohodu stradao, upravo od ruke vlastitog ujaka, koji ga je otrovao i sahranio ispod visoke jele. Ovo je Uroševa majka saznala od jednog kaluđera koji joj je rekao sledeće:

\footnotetext{
${ }^{30}$ M. Bahtin, op. cit., str. 29.
} 
Bog t' ubio, Uroševa majko,

Ako njega suzama poliješ,

Ti se na njeg' groktom nasmejavaj.

Da bi objasnio ovaj neobični smeh, Čajkanović zalazi u oblast uporedne religije i to direktno u grčku starinu u kojoj se prvi put pojavljuje izraz koji se i danas koristi u mnogim jezicima, pa i u našem - sardonični smeh, tj. sardonios, ili sardanios gelôs. Iako ova fraza još od grčke antike i Homera ${ }^{31}$ podrazumeva smeh koji je ironičan, Čajkanović upućuje na drugačije poreklo ove fraze. Reč je o starom sardinijskom običaju prema kome su ljude, za koje su procenili da su dostigli lepu starost, postavljali na ivicu groba i ubijali cepanicom. Čajkanović navodi i druge primere u kojima je ubistvo tj. smrt praćena smehom, poput žrtvovanja dece u Kartagini i u Misiriji. Pored toga, spominje se i godišnje žrtvovanje farmaka u Atini, koji su u prvo vreme ubijani, a kasnije proterivani iz grada. Ono što je za nas važno je da su ove atinske žrtve koje su preuzimale na sebe grehe čitavog društva, mogle biti uspešne jedino ako ih je pratilo dobro raspoloženje i smeh. Zanimljivo je da slične primere, upravo polazeći od sardonijskog smeha, navodi i Vladimir Prop, izvodeći isti zaključak kao i Veselin Čajkanović, a to je da se nikako ne radi o smehu koji je podrugljiv kako se često smatra, već je to smeh, kako zaključuju oba naučnika (i to verovatno nezavisno jedan od drugoga), koji je životvoran, tj. povezan sa smrću koja se transformiše u život ${ }^{32}$. Ovu tezu Prop izvodi, ali je Čajkanović razrađuje do detalja, uzevši u obzir više primera ubijanja dece i starih ljudi od Propa. U Rimu je npr. postojala fraza sexagenarii de pontes - koja znači ,„sezdesetogodišnjaci koje guraju sa mosta”, ${ }^{, 3}$ - koja je upućivala na ritualno ubijanje šezdesetogodišnjaka. Plinije navodi da je bilo veoma časno u galskim i britanskim provincijama ubiti stare ljude, čak i pojesti $i^{34}$, a Strabon spominje sličan običaj na ostrvu Keos ${ }^{35}$. Upravo

${ }^{31}$ Homer, Odiseja, prev. M.N. Đurić, Novi Sad 1976, str. 20, 301.

${ }^{32}$ V. Propp, Problemy komizma i smeha, Moskva 1999, str. 237.

${ }^{33}$ M. Tullius Cicero, For Sextus Roscius of Ameria, ed. by A. Clark, A. Curtis Clark, <www.perseus.tufts.edu> [preuzeto: 19.6.2012].

${ }^{34}$ Plinius, Naturalis Historiae, ed. by K. Friedrich, T. Mazhoff, knj. XXX, Leipzig 1906.

${ }^{35}$ Strabo, Geography, transl. H.C. Hamilton, W. Falconer, book X, London-New York 1903. 
ovi primeri navode Čajkanovića na zaključak o tome da je lapot u srpskoj tradiciji zaista postojao. Što se argumentacije tiče, ono što značajno govori u prilog Čajkanovićevoj tvrdnji je da su stari ljudi u tradicionalnim društvima bili veoma poštovani i da su shodno tome imali mnogo privilegija i časti. U tom smislu, ova ritualna ubistva on ne smatra ekonomski motivisanim, već ih povezuje sa nekadašnjim sistemom verovanja u kome je svaki ritualni čin imao snažan motiv i smisao za zajednicu. Naime, na osnovu verovanja da su pokojnici u zagrobnom životu zadržavali oblik i snagu kakvu su imali u trenutku smrti, ubijanje staraca pre nego što bi nastupila potpuna slabost i bolest obezbeđivala bi još uvek moćne i snažne zaštitnike u kultu mrtvih koji su kao takvi mogli obezbediti više sreće svojim potomcima. Dakle, smeh koji se javljao u kontekestu ovih ritualnih ubistava bio je kao prvo znak dobrog raspoloženja žrtve, a to je neophodan uslov za uspeh ritualnog žrtvovanja. Pored toga, a to je za nas ključno, smeh je najsnažnija manifestacija života i onaj ko u Onostrano uđe nasmejan, takav će i ostati, stekavši na taj način besmrtnost i obezbeđujući podršku prokreativnim životnim silama ${ }^{36}$.

Ovo nas vraća na prvi stih „Voj mi oca, ubio sin oca, ako da Bog - i ja ću mog!" koji u novom kontekstu u kome smo posmatrali značenje magijskog smeha (termin Veselina Čajkanovića), a u vezi sa ritualom ubijanja starih ljudi, možemo shvatiti ne kao puku šalu, već kao trag izumrlog običaja $^{37}$ čija se ritualna funkcija ne razlikuje mnogo od opscenosti iz stihova koji slede. U oba slučaja, reč je o ritualnoj podršci osnaživanja životnih sila - u prvom slučaju putem direktnog spominjanja smrti, a u drugom kroz magičnu moć opscenih šala koje, prema Bahtinu, snižavaju u sferi ma-

${ }^{36}$ V. Čajkanović, Studije iz sprske religije i folklora 1910-1924, Beograd 1994, str. $292-311$.

${ }^{37} \mathrm{U}$ srpskoj etnologiji ne postoji konsenzus oko toga da li je lapot (kako se drugačije zove bupe-lupe, a u Crnoj Gori pustenovanje) zaista postojao ili ne, ali upravo argumenti koje navode Veselin Čajkanović i Sava Prvanović, uvodeći i brojne slične primere iz drugih kultura, upućuju na zaključak da nije reč o legendi. V. Čajkanović, op. cit. Cf. S. Prvanović, Lapot - običaj ubijanja staraca, u: idem, Timočki zapisi, Zaječar-Timok 1964, str. 8-22. Suprotnog su mišljenja Radenko Ljubinković i Bojan Jovanović: B. Jovanović, Tajna lapota, Beograd 1999, str. 197; Lj. Radenković, Slovenska predanja o ubijanju staraca u kontekstu kulture, Novi Sad 2003, str. 217-236. Film Legenda o lapotu snimljen je 1972. godine u režiji Gorana Paskaljevića, čime je ova teme privukla pažnju i šire javnosti. 
terijalno-telesnog sa značenjem spuštanja u grob ${ }^{38}$. I jedno i drugo ima identičnu funkciju, da kroz smrt - faktičku ili simboličku, dovedu do preporoda i novog života ${ }^{39}$. I jedno i drugo povezuje magijski smeh. Ovaj smeh, kako naglašava Bahtin, nikada nije satiričan, već ,izražava gledište čitavog sveta u nastajanju, kojem pripada i onaj koji se smeje" ${ }^{40}$. Upravo zbog činjenice da je reč o smehu koji ne poznaje hijerarhiju i koji ne ismeva iz prezira, već s motivacijom smehovnog preporoda, ruše se apsolutno sve granice i autoriteti.

\section{Zaključak}

U ovom radu sam opsceni (pre svega jezički) sadržaj revene upisala u čuvenu Bahtinovu teoriju smehovne kulture ${ }^{41}$. Ovoj svetski poznatoj teoriji dodala sam i konceptualizaciju magijskog smeha Veselina Čajkanovića čime su zapravo oba tumačenja dobila novu, osnažujuću argumentaciju. Naime, prema Veselinu Čajkanoviću, magijski smeh je vrsta ritualnog smeha koji je vezan za smrt i javlja se u pogrebnom ritualu. Iako nije spontan, taj je smeh značajan kao životvorni element koji je umešten u pogrebne rituale, naročito mladih ljudi, ali se u tradiciji različitih naroda može pronaći i u ritualnom žrtvovanju ljudi. Iako Bahtin ne analizira pogrebne rituale, on smeh tumači kroz različite vrste snižavanja i spuštanja na materijalno-telesni nivo, čime zapravo vrši metaforičko povezivanje sa

${ }^{38}$ M. Bahtin, op. cit., str. 29.

${ }^{39}$ Smeh je u pogrebnom ritualu i dalje neizostavni deo daće i bdenja (koje se još uvek zove bdenje iako ne podrazumeva čuvanje pokojnika, već posetu ožalošćenima uoči sahrane i izjavljivanje saučešća koje može trajati i u toku noći). On danas, posebno nakon sahrane, kada se jede i pije u izobilju, na grobu, u kafani ili u pokojnikovoj kući, često izaziva zbunjenost, pa čak i gađenje. Zanimljivo je da je kao i u narodnoj pesmi, ovaj smeh bio posebno značajan na sahranama mladih ljudi o čemu postoje brojna svedočanstva. Vidi više u L. Stevanović, Laughing at the Funeral: Gender and Anthropology in Greek Funerary Rites, Beograd 2009, str. 320.

${ }^{40}$ M. Bahtin, op. cit., str. 19.

${ }^{41}$ U sličnom ključu su Bahtinovu teoriju primenile na erotsku i narodnu poeziju Zoja Karanović i Jasmina Jokić u knjizi Smehovno i erotsko u srpskoj narodnoj kulturi i poeziji, Novi Sad 2009. 
smrću, koja je, kao i kod Čajkanovića, shvaćena kao preduslov života. Bahtin se bavi smehovnom kulturom koja se ispoljava u tradicionalnoj kulturi na razne načine, a ja sam u ovom radu navele neke od njih. Ona nastaje kroz snižavanje sveta na materijalno-telesni nivo, u kome je čitava priroda izmešana i u stalnom procesu promene - kroz smrt, rađanje, seksualne činove; kroz jedenje, pijenje, pražnjenje creva. Sve to je preterano i hiperbolizovano, a dešava se kroz telo pojedinca koje zapravo nosi kosmičku simboliku promene, izazivajući smeh i transformišući smrt u novi život. 